\title{
Clinical, microbiological and oxidative stress evaluation of periodontitis patients treated with two regimens of systemic antibiotics, adjunctive to non-surgical therapy: A placebo-controlled randomized clinical trial
}

\author{
SIMINA BOIA ${ }^{1}$, MARIUS BOARIU $^{2}$, FLAVIA BADERCA ${ }^{3}$, DARIAN RUSU ${ }^{1}$, DELIA MUNTEAN $^{4}$, \\ FLORIN HORHAT $^{4}$, EUGEN-RADU BOIA ${ }^{5}$, CLAUDIA BORZA ${ }^{6}$, ANDREI ANGHEL ${ }^{7}$ and ŞTEFAN-IOAN STRATUL $^{1}$ \\ Departments of ${ }^{1}$ Periodontology and ${ }^{2}$ Endodontics, Faculty of Dental Medicine, 'Victor Babeş' University of \\ Medicine and Pharmacy; Departments of ${ }^{3}$ Histology, ${ }^{4}$ Microbiology, ${ }^{5}$ ENT, ${ }^{6}$ Pathophysiology and ${ }^{7}$ Biochemistry, \\ Faculty of Medicine, 'Victor Babeş' University of Medicine and Pharmacy, 300041 Timişoara, Romania
}

Received May 30, 2019; Accepted July 25, 2019

DOI: $10.3892 / \mathrm{etm} .2019 .7856$

\begin{abstract}
Aim of research was to evaluate and compare the clinical and microbiological effects of two different regimens of amoxicillin (AMX) and metronidazole (MTZ) combined with non-surgical periodontal therapy in patients with chronic periodontitis (CP), and identify antibiotic-resistant bacteria and changes in oxidative stress (OS). Forty-six patients with generalized CP were randomly assigned to group A [scaling and root planing within $24 \mathrm{~h}$ (SRP) + placebo for 7 days), group B [SRP + AMX + MTZ, both $500 \mathrm{mg}$ three times daily (TID), 3 days), and group C [SRP + AMX + MTZ, both $500 \mathrm{mg}$ TID, 7 days). Periodontal pocket depth (PPD-primary outcome), clinical attachment level (CAL), full-mouth bleeding scores (FMBS), plaque scores (FMPS), blood and subgingival plaque were assessed at baseline and after three months. OS was evaluated via derivatives of reactive oxygen metabolites (d-ROMs) and assessments of biological antioxidant potential (BAP). Bacterial profiling was performed by PCR. Antibiotic resistance was evaluated in cultures. PPD, CAL, number of sites with PPD $\geq 6 \mathrm{~mm}$, their PPD, CAL and FMBS decreased $(\mathrm{P}<0.05)$ in all groups, as well as FMPS in groups A and B, and d-ROMs in group C. There were significant differences among groups regarding decreases in the frequency of detection for $A a$ and $T f$. For $A a$, there were differences between groups $\mathrm{A}$ and $\mathrm{C}(\mathrm{P}=0.048)$ and between groups $\mathrm{B}$ and $\mathrm{C}(\mathrm{P}=0.048)$, but not between groups $\mathrm{A}$ and $\mathrm{B}$;
\end{abstract}

Correspondence to: Dr Marius Boariu, Department of Endodontics, Faculty of Dental Medicine, 'Victor Babeş' University of Medicine and Pharmacy, 9 Bulevardul Revolutiei din 1989, 300041 Timișoara, Romania

E-mail: boarium@yahoo.com

Key words: periodontitis, bacteria, root planing, antibiotics, antibiotic resistance, oxidative stress whereas for $T f$, groups A and B were different from group C $(\mathrm{P}<0.001)$, but not from each other $(\mathrm{P}=0.920)$. No resistance to AMX was identified prior to treatment; two strains were resistant after treatment. Before treatment, 13 strains were resistant to MTZ, and 2 were resistant after. One strain in the same patient was sensitive prior to treatment, and later became resistant to both antibiotics. SRP with a 7-day course of antibiotic therapy was more effective for improving clinical parameters, in decrease of detection of several periopathogens, and in improvement of OS when compared to a 3-day regimen. Resistance was found in fewer strains after treatment than before.

\section{Introduction}

Homeostasis of tissues affected by periodontal disease is achieved by the mechanical removal of bacterial deposits on the surface of teeth by scaling and root planing (SRP) (1). However, this procedure cannot remove residual bacteria in root locations that are inaccessible to mechanical instrumentation; therefore, subgingival biofilm cannot be completely eliminated (2-4). The insufficient reduction of bacteria is associated with therapeutic failures, and the persistence of bacterial species after mechanical debridement has been associated with additional tissue destruction (4-6). Under these conditions, the use of systemic antibiotics as an adjunct to initial periodontal therapy may be helpful, especially because the disruption of biofilm by mechanical instrumentation makes bacteria more susceptible to antibiotics (7). Until recently, the antibiotic combination of amoxicillin (AMX) plus metronidazole (MTZ) administered for 7-8 days has been the protocol most widely used to achieve clinical and microbiological efficacy (8-18). However, despite the impressive amount of research that has demonstrated the beneficial effects of the AMX + MTZ combination as an adjuvant to SRP, there is still no consensus in the literature concerning the optimal duration and antibiotic dosing. Various adjunctive regimens of AMX + MTZ have been proposed. In the 
literature, the durations of systemic treatment with MTZ, AMX or their combination range from $7-8$ days $(6,8,10,13-16,19)$ to 10-14 days (20-25). When both the duration of administration and the doses are considered, the variation in study design is even greater. The only exception appears to be the dose of AMX, which in the vast majority of studies is $500 \mathrm{mg}$ per day, three times daily (TID) $(12,17,18,20-26)$. On the other hand, the recommended ideal dose of MTZ has been cited as 200, 250,400 or $500 \mathrm{mg}$ TID $(8,13,19-24)$. Current authoritative textbooks of Periodontology based on reputed papers (27) still recommend using the $250 \mathrm{mg}$ TID dose regimen of both AMX and MTZ to treat periodontal diseases (28). However, regardless of the dose and duration, it is important that antibiotics be taken at their minimum bactericidal concentration (29) to limit the risk for side effects and the development of microbial antibiotic resistance (4).

Antibiotics have paved the way for unprecedented medical and societal developments, and are now widely used by all health systems (31). In recent decades, the global emergence of antimicrobial resistance has become a pre-eminent concern among medical and public health professionals, as well as a widespread problem. The causative factors for this resistance remain uncontrolled, and national strategies to address the problem are lacking (32). Recently, substantial changes have been proposed to the adjuvant systemic antibiotic administration protocol used to treat patients with chronic periodontitis. In studies evaluating exclusively the change in clinical parameters in patients with chronic periodontitis, the proposed changes have reduced the duration of antibiotic intake from 7 to 3 days, and increase the dose from $3 \times 250-375 \mathrm{mg} /$ day to 3 x $500 \mathrm{mg} /$ day $(4,30)$. These modifications are controversial due to the possibility that periopathogenic bacteria might develop antibiotic resistance. Currently, the antibiotic resistance of periopathogens exposed to adjunctive systemic antibiotics after SRP has been insufficiently addressed in the literature. Most investigators who have addressed this issue identified naturally resistant bacteria prior to periodontal therapy (33-37). In the USA, patients with $\mathrm{CP}$ frequently harbor subgingival periodontal pathogens that display in vitro resistance to therapeutic concentrations of antibiotics that are commonly used in clinical periodontal practice (33). Moreover, the different species of periodontal pathogens often have different susceptibilities to particular antibiotics (38). Few authors have investigated the resistance of periopathogenic bacteria to antibiotics both before and after periodontal treatment. However, the existing studies show that despite the initial antibiotic resistance of some species, most periopathogens are sensitive to antibiotics during their administration, and systemic antibiotics reduce the number of resistant strains at the end of non-surgical periodontal therapy, when compared with the initial situation $(34,36,37)$.

In periodontal disease, pathogens such as Porphyromonas gingivalis, Treponema denticola, and Tannerella forsythia interact with the host organism and produce a systemic inflammation, which affects the tissue balance through the action of a large number of cytokines and chemokines released by normal connective tissue residents such as mast cells, fibroblasts or by acquired connective tissue participants such as activated macrophages (39).
Recently, a Gram-positive, non-spore-forming, nonmotile and strictly anaerobic rod (Slakia exigua) has been isolated and identified in periodontal and periapical infections, as well (40). The induction of pro-inflammatory cytokines, chemokines, and an enhanced immune response, through mast cell degranulation, with subsequent histamine and pro-inflammatory cytokines release can amplify the inflammatory process and result in an increase in the number and activity of polymorphonuclear cells (PMNs) (41,42). PMNs produce reactive oxygen species (free radicals) via the respiratory burst mechanism as part of a defense response to infection (43). The deliberate generation of free radicals occurs during phagocytosis as part of the bactericidal reaction (44). The production of reactive oxygen species is a component of the bone resorption process that occurs during periodontal disease $(41,43)$, and contributes to its aggravation. However, the source of reactive oxygen species and their role in the pathogenesis of periodontitis remain unclear (45). Studies in human subjects (46-49) have revealed that periodontal disease is associated with systemic oxidative stress that induces some minor localized inflammation. Currently, the 3-day systemic antibiotic adjunctive regimen used in non-surgical periodontal therapy has been compared with a 7-day regimen in only two studies conducted by the same investigators who only evaluated changes in clinical periodontal parameters $(4,30)$.

In this study, we compared various periodontal clinical parameters, microbiological changes, and systemic oxidative stress in patients with chronic periodontitis who received adjuvant systemic administration of AMX and MTZ following non-surgical periodontal therapy. These comparisons were made between groups of patients who received short-term (3 days) or long-term (7 days) antibiotic treatment regimens. Additionally, we assessed changes in the resistance of subgingival pathogens to the prescribed antibiotics before and after their use in periodontal treatment.

\section{Patients and methods}

Between October 2017 and August 2018, this prospective, placebo-controlled, triple-blinded, randomized clinical trial enrolled 46 subjects who were outpatients at the Clinic of Periodontology of the Faculty of Dental Medicine of the 'Victor Babeş' University of Medicine and Pharmacy in Timișoara, Romania. The study protocol was approved by the Research Ethics Committee of the 'Victor Babeş' University of Medicine and Pharmacy (approval no. 06/07.05.2018). The study is registered in the ISRCTN Registry of Clinical Trials (ISRCTN12816166), and follows the guidelines described in the CONSORT 2010 statement on clinical trials. The study was conducted over a period of 14 months (October 2017-December 2018) in accordance with principles outlined in the Declaration of Helsinki on experimentation involving human subjects. All subjects were informed about the nature and purpose of the study, and each subject signed an informed consent document giving permission for the dental procedures and sampling of biological material.

Patient population. The study population consisted of males and females (mean age, $46.24 \pm 12.81$ years; range, $27-80$ years) who had clinical and radiographic signs of generalized chronic 
periodontitis (CP), as described by Armitage in 1999 (50). The study eligibility criteria included the presence of at least 10 natural teeth that were distributed in all four quadrants. Among the teeth, at least six had to exhibit one site with a pocket depth (PD) $\geq 5 \mathrm{~mm}$ at baseline. Subjects who had received periodontal therapy or taken an antibiotic during the previous six months were excluded from the study. Other exclusion criteria included: any systemic disorder that might affect the progression and treatment of periodontal disease (eg. diabetes type 1 or 2), taking a medication that might interact with amoxicillin or metronidazole (eg. coumarin derivatives, alcohol derivatives, 5-fluorouracil/disulfiram derivatives, oral solutions with amprenavir, lopinavir/ritonavir, methotrexate or tetracyclines, oral contraceptives, mebendazole, busulfan, timidazole, vitamin $\mathrm{K}$ antagonists, barbiturates and lithium), pregnancy and lactation. To be classified as a smoker, the subject had to report smoking >10 cigarettes per day (Tonetti et al 1995) (51).

Clinical measurements. All patients underwent a clinical and radiographic baseline (before therapy) examination that assessed the following parameters: Periodontal pocket depth (PPD), clinical attachment level (CAL), full mouth bleeding score (FMBS), and full-mouth plaque score (FMPS). The evaluation results were recorded in a periodontal chart (http://www.periodontalchart-online.com/uk/) that was subsequently saved in a pdf format, printed, and attached to the patient's observation file. Three months later, measurements of PPD and the CAL were made at six sites per tooth (mesio-buccal, buccal, disto-buccal, disto-lingual, lingual, and mesio-lingual) at all teeth, excluding third molars, to the nearest millimeter with a periodontal probe (PCPUNC 15; $\mathrm{Hu}$-Friedy), and using the cement-enamel junction (CEJ) as a reference point for CAL. When the CEJ was missing, measurements were made by using the most apically located margin of the restoration as a reference point. Tooth mobility was assessed based on the Miller classification system (1985) (52), and furcation involvement (FI) was assessed by using a Nabers probe \#2N hdl \#7, markings: 3-6-9-12 mm, (Hu-Friedy ${ }^{\circledR}$ ), with the results classified according to Hamp et al 1975 (53).

After completing the measurements, all pockets with PPD $\geq 4 \mathrm{~mm}$ were scaled and root planed under local anesthesia with Gracey curettes (Hu-Friedy ${ }^{\circledR}$ ) and ultrasonic instruments (Piezon ${ }^{\circledR} 250$; Electro Medical Systems SA) by the same clinician (SB) who followed the protocol used for One-Stage Full-Mouth Disinfection-OSFMD (54). As home care, the patients were advised to rinse their mouth twice daily for 2 min with a $0.2 \%$ chlorhexidine digluconate solution (Dentaton; Ghimas S.p.A.) for 14 days.

Randomization, blinding, and treatment allocation. At the end of the non-surgical therapy session, one investigator (the randomizer, SIS) used a number generator (www.random.org) to assign each patient to one of three treatment groups. Each position on the randomization list was associated with a medication package number that corresponded to a pre-packed medication bag that contained instructions for medication intake. One bag was handed to each patient. The patients in group A (control group, $n=14$ ) received non-surgical periodontal treatment plus treatment with placebos for 7 days. Patients in group B $(n=16)$ received non-surgical periodontal treatment combined with the systemic administration of AMX and MTZ (SRP + AMX + MTZ; 500 mg, TID) for 3 days, followed by treatment with placebos for 4 days. Patients in group $\mathrm{C}$ (test group, $\mathrm{n}=16$ ) received non-surgical periodontal treatment combined with SRP + AMX + MTZ (500 mg TID) for 7 days.

Each medication bag contained four identical vials, and each vial contained tasteless and identical types of capsules. Each vial was numbered, and the patient was instructed to take one capsule from each vial every $8 \mathrm{~h}$ as follows: from vials no. 1 and 2 during the first 3 days after SRP, and from vials no. 3 and 4 during the following 4 days. The placebo group (group A) had only placebo capsules in all the vials. Group B had AMX and MTZ in vials no. 1 and 2, and placebo in vials no. 3 and 4. Group C had AMX and MTZ in all four vials. The medication bags were prepared by the pharmacy of the University of Medicine and Pharmacy 'Victor Babeş'. A followup appointment was scheduled for 2 weeks after each patient had begun taking their medication. During that appointment, each patient was asked whether they had experienced any adverse reaction or breached the study's inclusion criteria. The SB, the SIS and the patients were blinded against the antibiotic regimens.

Microbiological sampling. During the initial evaluation, samples of subgingival plaque were collected from the deepest periodontal pockets in each quadrant and used to identify the existing bacterial strains and their resistance to systemic antimicrobial agents prior to treatment. This protocol was repeated at the three-month re-evaluation to assess post-treatment bacterial suppression and identify strain resistance after long- or short-term antibiotic intake periods. Samples were collected by using eight sterile paper points (ProTaper Next ${ }^{\circledR}$ Paper Points X2; Dentsply Sirona) that were inserted into the gingival sulcus after having removed any supragingival plaque with sterile cotton gauzes, isolated the site with cotton rolls, and taken measures to avoid contamination with saliva. After the targeted tooth surface was dried with a gentle air spray, the paper points were left in situ for $30 \mathrm{sec}$ until they were completely soaked.

Eight paper points were inserted in each patient, and four of those paper points were inserted into sterile sealed Eppendorf tubes and sent for polymerase chain reaction (PCR) testing that was performed with a commercial Micro-Ident ${ }^{\circledR}$ Kit (Hain Lifescience $\mathrm{GmbH}$ ). The samples were tested for the following bacterial strains: Aggregatibacter actinomycetemcomitans (Aa), Porphyromonas gingivalis (Pg), Prevotella intermedia (Pi), Tanererella forsythia (Tf), and Treponema denticola $(T d)$. The PCR testing was conducted at the laboratories of the Department of Biochemistry of the 'Victor Babeş' University of Medicine and Pharmacy. Following 15 min of vortex mixing at room temperature, the cones were removed and the eluates clarified by centrifugation for $5 \mathrm{~min}$ at $3,000 \mathrm{x}$ g at $23^{\circ} \mathrm{C}$. The samples were stored for 1 day at $-20^{\circ} \mathrm{C}$, and then at $-80^{\circ} \mathrm{C}$ until a microbiological analysis was performed no more than 30 days later.

Genetic identification of periodontopathogenic bacterial species and assessment of antimicrobial resistance. DNA was extracted by using a QIAamp DNA Micro Kit (Qiagen GmbH) 
Table I. Patient demographic characteristics at baseline and P-values.

\begin{tabular}{lcccc}
\hline Characteristics & Group A & Group B & Group C & P-value \\
\hline Number of patients (no.) & 14 & 16 & 16 & - \\
Age (years) & $46.71 \pm 12.99$ & $51.88 \pm 14.51$ & $40.19 \pm 7.90$ & $0.052^{\mathrm{a}}$ \\
(min-max) & $(30-67)$ & $(33-80)$ & $(27-54)$ & \\
Females (\%) & $9(64.29)$ & $5(31.25)$ & $9(56.25)$ & $0.21^{\mathrm{b}}$ \\
Smokers (\%) & $4(28.57)$ & $7(43.75)$ & $2(12.50)$ & $0.147^{\mathrm{b}}$ \\
\hline
\end{tabular}

${ }^{\mathrm{a}}$ Kruskal-Wallis test; ${ }^{\mathrm{b}}$ Fisher exact test for proportions.

according to the manufacturer's protocol. The absolute yield and quality of the extracted DNA were assessed by using a NanoDrop ND-1000 spectrophotometer (Thermo Fisher Scientific Inc.). Semiquantitative assessments of bacteria were performed using a commercial testkit-system (micro-IDent plus; Hain Lifescience $\mathrm{GmbH}$ ). Amplification was performed in a thermocycler (Thermo Fisher Scientific Inc.) and using HotStar Taq polymerase (Qiagen $\mathrm{GmbH}$ ). Results were recorded and classified into the following categories: 0 , nondetectable; $1,10^{4}\left(10^{3}\right.$ for $\left.A a\right)$; $2,10^{4}-10^{5}\left(10^{3}-10^{4}\right.$ for $\left.A a\right)$; $3,10^{5}-10^{6}\left(10^{4}-10^{5}\right.$ for $\left.A a\right)$; and $4,>10^{7}\left(10^{6}\right.$ for $\left.A a\right)$.

The other four paper points were placed in vials that contained thioglycolate and resazurin (bioMérieux ${ }^{\circledR}$ ) and sent to the laboratories of the Department of Microbiology within $1 \mathrm{~h}$ after sampling. The inoculated thioglycolate tubes were agitated for $30 \mathrm{sec}$, and the homogenized samples were seeded into Columbia-agar plates and Schaedler-agar plates (bioMérieux ${ }^{\circledR}$ ) (0.2 ml per plate). For Aa, TSBV (Triptic SoySerum-Bacitracin-Vancomycin-Agar) (55) plates were used. After seeding, the plates were incubated under anaerobic conditions at $37^{\circ} \mathrm{C}$ (GENbag anaero; bioMérieux) for $48 \mathrm{~h}$, after which, they were re-incubated and evaluated for 7 days. The different strains of bacteria were identified by using ViteK2 ANC Kits (bioMérieux ${ }^{\circledR}$ ) (as recommended in similar identification protocols) $(56,57)$, and Rapid ID 32A Kits (bioMérieux ${ }^{\circledR}$ ). Bacterial resistance to antibiotics was evaluated by comparing the identified bacterial strains, at baseline and at three months. The minimum inhibitory concentrations (MICs) for AMX and MTZ were determined by using the Epsilometer technique (E-test ${ }^{\circledR}$; AB Biodisk), on Brucella Blood Agar plates (bioMérieux ${ }^{\circledR}$ ). The MIC values were expressed in units of $\mu \mathrm{g} / \mathrm{ml}$ and were determined by evaluating a drug concentration range of 0.02 to $256 \mu \mathrm{g} / \mathrm{ml}$, and are expressed in units of $\mu \mathrm{g} / \mathrm{ml}$. A control strain (Bacteroides fragilis, ATCC 25285, Thermo Fisher Scientific) was also tested for its identification and sensitivity to the antibiotics.

Oxidative stress assessment. Blood samples $(1.3 \mathrm{ml})$ were collected from the antecubital vein between 8:00 a.m. and 10:00 a.m., and transported to the laboratories of the Department of Pathophysiology of the 'Victor Babeş' University of Medicine and Pharmacy within one hour after the venipuncture. The samples were centrifuged for $10 \mathrm{~min}$ at $20^{\circ} \mathrm{C}$ at 2,057 x g. The supernatant was collected in an Eppendorf tube and stored at $-80^{\circ} \mathrm{C}$ until analysis. The derivatives reactive oxygen metabolites (d-ROM) test and biologic antioxidant potential (BAP) test were used to analyze reactive oxygen metabolites and biological antioxidant potential, respectively, by use of photometric methods (Diacron International ${ }^{\circledR}$ ).

Supportive periodontal treatment (SPT). SPT was performed by the same clinician (SB) in all patients on a three-month follow-up basis, The SPT consisted of supra- and subgingival debridement by use of ultrasonic mechanical instrumentation and prophylactic powder AIR FLOW ${ }^{\circledR}$ CLASSIC powder (EMS) at all sites, in order to enhance biofilm removal. During the follow-up appointment, various clinical parameters (PPD, CAL, FMPS, FMBS, FI, and tooth mobility), biochemical parameters (d-ROM and BAP), and microbiological changes ( $\mathrm{Aa}, \mathrm{Pg}, \mathrm{Pi}, \mathrm{Tf}, \mathrm{Td}$ and bacterial resistance) were recorded. If necessary, individual oral hygiene was reinforced.

Intra-examiner reproducibility. In order to evaluate the intra-examiner reproducibility of clinical data, five subjects who were not involved with the study but satisfied the enrollment criteria were evaluated on two occasions, $24 \mathrm{~h}$ apart. The intraclass correlation coefficient (ICC) was used to assess the agreement of findings, based on the PD measurements. The ICC was calculated using the R package irr (59). An intra-examiner agreement of 0.989 (95\% CI, 0.916-0.999) was found.

Statistical analysis. All statistical analyses were performed using R software, v. 3.4.0 (58). Comparisons of clinical and microbiological parameters were performed within each group (between the baseline and 3-month re-evaluation), and also between groups. Changes between appointments $(\Delta)$ were calculated as the difference between the initial and final value of each parameter. The primary outcome was the intergroup difference in reduction of PPD after intervention, while CAL, FMPS, FMBS, number of sites with a PPD $\geq 6 \mathrm{~mm}$ (considered deep periodontal pockets), and the microbiological parameters were regarded as secondary outcomes. In order to achieve $80 \%$ power for detecting a significant mean difference of $1 \mathrm{~mm}$ in the reduction of PPD between groups (assuming a common standard deviation of $0.75 \mathrm{~mm}$ and given significance level $\alpha=0.05$ ), at least 14 patients needed to be included in each group. The Pitman asymptotic relative efficiency correction was applied in the sample size computation to account for the use of nonparametric comparison tests. Changes in the frequency of detection of major periopathogens were analyzed to evaluate the microbiological status of the patients. 


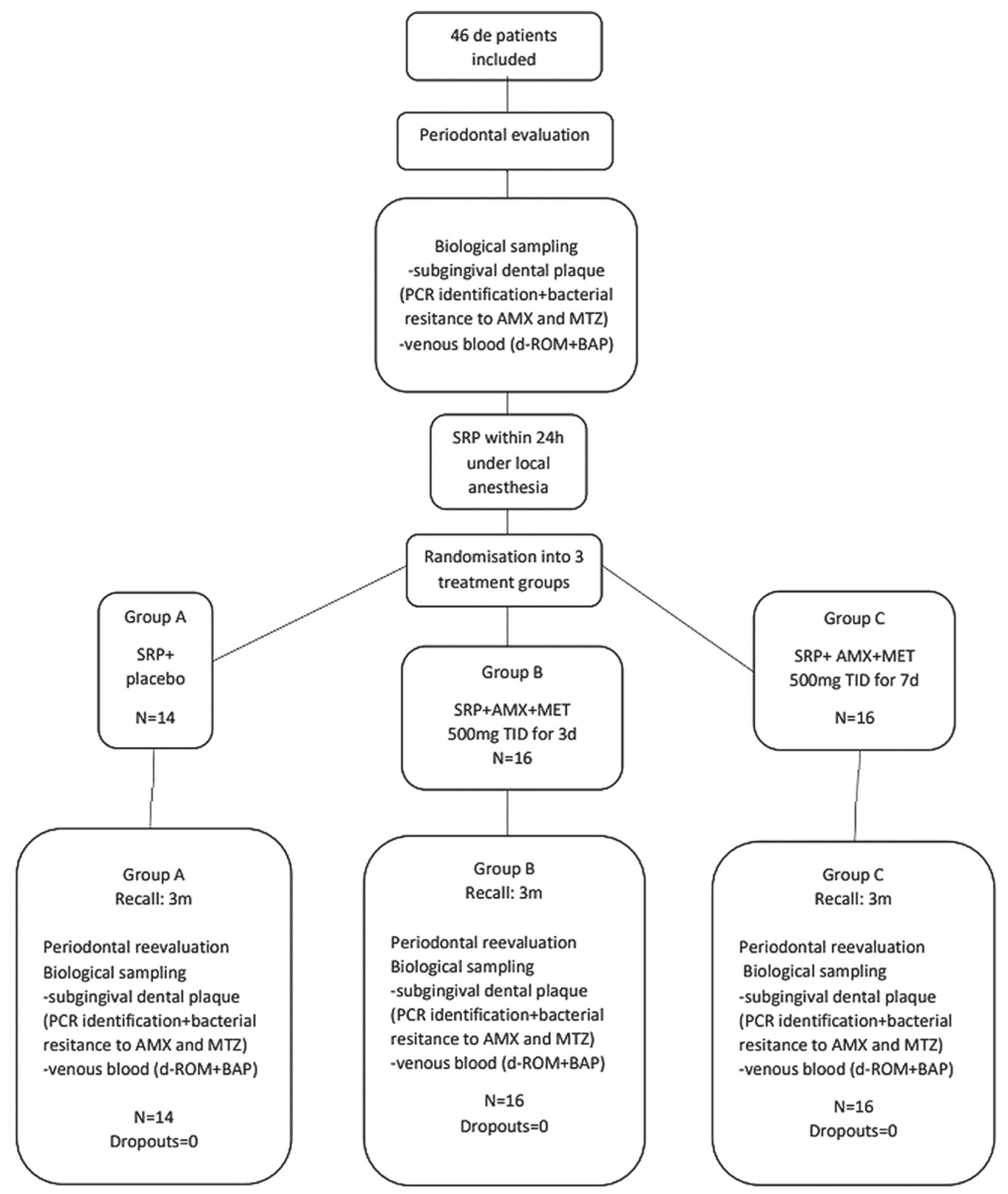

Figure 1. Flow-chart of the study protocol. SRP, scaling and root planing; AMX, amoxicillin; MET, metronidazole; PCR, polymerized-chain reaction; $\mathrm{d}-\mathrm{ROM}$, derivatives of reactive oxygen metabolites; BAP, biological antioxidant potential; TID, three times daily.

Inter-group comparisons were made using Kruskal-Wallis tests with post-hoc Mann-Whitney tests for quantitative and ordinal variables, and Fisher exact tests for proportions. The Benjamini-Hochberg method was used to adjust P-values in multiple comparisons. Additionally, comparisons among groups regarding changes that occurred in various parameters between appointments after adjusting for baseline values and smoking were made by rank-based ANCOVA (60) as performed with the R package npsm (61). The absence of interactions between groups and covariates (i.e. homogeneity of regression slopes) was tested before considering adjusted inference. Intra-group comparisons of clinical and biochemical parameters and detection scores of pathogen species ( $A a$, $P g, P i, T d, T f$ ) between the baseline and 3 month re-evaluation time-points, were performed using Wilcoxon Signed Rank tests. In all analyses, a P-value $<0.05$ was considered to be statistically significant.

\section{Results}

Patient population. The patient demographic characteristics are described in Table I. The study enrolled 46 patients (23 females and 23 males) with a mean age of $46.24 \pm 12.81$ years. Among the enrolled patients, $28.26 \%$ were smokers. No patient withdrew from the study during its investigational period (Fig. 1), and no adverse events attributable to treatment were reported.

Changes in clinical parameters. The PPD, CAL, and FMBS values, the incidence of deep pockets (PPD $\geq 6 \mathrm{~mm}$ ) and the corresponding CAL, and the number of sites with a PPD $\geq 6 \mathrm{~mm}$, all showed significant changes between the initial and final evaluation in all three treatment groups. We also found significant decreases in FMPS in groups A and B, but not in group $\mathrm{C}$ (Table II). The mean baseline values for the clinical parameters in the different study groups are shown in Table III.

The baseline values for PPD and CAL showed significant differences between groups (Table III). Post-hoc Mann-Whitney tests revealed that the PPD values in group A were lower than those in groups $\mathrm{B}$ and $\mathrm{C}(\mathrm{P}=0.041$ in both cases $)$, whereas the baseline PPD values in groups $\mathrm{B}$ and $\mathrm{C}$ were similar $(\mathrm{P}=1)$. Moreover, the values for CAL in group $\mathrm{A}$ were lower than those in groups $\mathrm{B}$ and $\mathrm{C}(\mathrm{P}=0.041$ in both cases $)$, and the latter two groups showed no significant difference in $\mathrm{CAL}$ 
Table II. Intra-group comparisons of clinical parameters before and after treatment, and the P-values of differences (Wilcoxon test).

\begin{tabular}{|c|c|c|c|c|}
\hline Parameters & Study group & Baseline & 3-months re-evaluation & P-value \\
\hline \multirow[t]{3}{*}{ PPD (mm) } & A & $3.11 \pm 0.96$ & $2.70 \pm 0.53$ & $0.007^{\mathrm{a}}$ \\
\hline & $\mathrm{B}$ & $3.71 \pm 0.77$ & $3.14 \pm 0.82$ & $0.002^{\mathrm{a}}$ \\
\hline & $\mathrm{C}$ & $3.75 \pm 0.86$ & $3.04 \pm 0.71$ & $<0.001^{\mathrm{a}}$ \\
\hline \multirow[t]{3}{*}{ CAL (mm) } & A & $3.47 \pm 1.19$ & $3.08 \pm 0.73$ & $0.017^{\mathrm{a}}$ \\
\hline & $\mathrm{B}$ & $4.38 \pm 1.19$ & $3.83 \pm 1.16$ & $0.001^{\mathrm{a}}$ \\
\hline & $\mathrm{C}$ & $4.56 \pm 1.89$ & $3.83 \pm 1.58$ & $<0.001^{\mathrm{a}}$ \\
\hline \multirow[t]{3}{*}{ FMPS $(\%)$} & A & $28.14 \pm 29.47$ & $11.50 \pm 12.91$ & $0.004^{\mathrm{a}}$ \\
\hline & $\mathrm{B}$ & $49.62 \pm 34.29$ & $25.25 \pm 22.26$ & $0.006^{\mathrm{a}}$ \\
\hline & $\mathrm{C}$ & $30.38 \pm 27.06$ & $21.56 \pm 20.77$ & 0.083 \\
\hline \multirow[t]{3}{*}{ FMBS (\%) } & A & $32.86 \pm 20.26$ & $16.79 \pm 10.53$ & $0.002^{\mathrm{a}}$ \\
\hline & $\mathrm{B}$ & $39.12 \pm 26.64$ & $19.81 \pm 11.20$ & $0.010^{\mathrm{a}}$ \\
\hline & $\mathrm{C}$ & $38.00 \pm 21.58$ & $15.75 \pm 9.55$ & $<0.001^{\mathrm{a}}$ \\
\hline \multirow[t]{3}{*}{ Number of sites with PPD $\geq 6 \mathrm{~mm}$} & A & $12.36 \pm 17.59$ & $4.21 \pm 5.32$ & 0.004 \\
\hline & $\mathrm{B}$ & $18.69 \pm 24.43$ & $7.56 \pm 11.27$ & $<0.001^{\mathrm{a}}$ \\
\hline & $\mathrm{C}$ & $20.25 \pm 14.14$ & $4.31 \pm 5.57$ & $<0.001^{\mathrm{a}}$ \\
\hline \multirow[t]{3}{*}{ CAL of sites with PPD $\geq 6 \mathrm{~mm}$} & A & $6.44 \pm 0.75$ & $4.97 \pm 1.04$ & $0.002^{\mathrm{a}}$ \\
\hline & $\mathrm{B}$ & $6.63 \pm 0.88$ & $4.55 \pm 1.34$ & $0.001^{\mathrm{a}}$ \\
\hline & $\mathrm{C}$ & $7.19 \pm 1.88$ & $4.95 \pm 1.59$ & $<0.001^{\mathrm{a}}$ \\
\hline
\end{tabular}

Values are presented as the mean $\pm \mathrm{SD}$. ${ }^{\mathrm{a}} \mathrm{P}<0.05$ a significant correlation. $\mathrm{PPD}$, periodontal pocket depth; CAL, clinical attachment level; FMPS, full-mouth plaque score; FMBS, full-mouth bleeding score.

Table III. Clinical characteristics of patients at baseline and the p-values for comparisons between treatment groups (Kruskal-Wallis test).

\begin{tabular}{|c|c|c|c|c|}
\hline Characteristics & Group A & Group B & Group C & P-value \\
\hline PPD (mm) & $3.11 \pm 0.96$ & $3.71 \pm 0.77$ & $3.75 \pm 0.86$ & $0.027^{\mathrm{a}}$ \\
\hline CAL (mm) & $3.47 \pm 1.19$ & $4.38 \pm 1.19$ & $4.56 \pm 1.89$ & $0.033^{\mathrm{a}}$ \\
\hline FMPS (\%) & $28.14 \pm 29.48$ & $49.62 \pm 34.29$ & $30.38 \pm 27.06$ & 0.139 \\
\hline FMBS (\%) & $32.86 \pm 20.26$ & $39.12 \pm 26.64$ & $38.00 \pm 21.58$ & 0.749 \\
\hline Mean number of sites with PPD $6 \mathrm{~mm}$ & $12.36 \pm 17.59$ & $18.69 \pm 24.43$ & $20.25 \pm 14.14$ & 0.095 \\
\hline PPD of sites with PPD $\geq 6 \mathrm{~mm}$ & $6.26 \pm 0.39$ & $6.56 \pm 0.85$ & $6.55 \pm 0.43$ & 0.170 \\
\hline CAL of sites with PPD $\geq 6 \mathrm{~mm}$ & $6.44 \pm 0.75$ & $6.63 \pm 0.88$ & $7.19 \pm 1.88$ & 0.203 \\
\hline
\end{tabular}

Quantitative data are expressed as the mean \pm standard deviation. ${ }^{\mathrm{P}}<0.05$ a significant correlation. PPD, periodontal pocket depth; $\mathrm{CAL}$, clinical attachment level; FMPS, full-mouth plaque score; FMBS, full-mouth bleeding score.

values $(\mathrm{P}=0.664)$. Table IV shows a comparison of changes that occurred in the different groups between the baseline and 3 months re-evaluation time-points. While more pronounced changes in PPD, CAL and FMBS, and greater decreases in PPD and CAL in initial deep sites were associated with a longer course of antibiotic intake, those differences were not statistically significant. There were, however, significant differences between groups with regard to the decrease in the number of sites with a PPD $\geq 6 \mathrm{~mm}$. Post-hoc tests showed these differences were due to a greater decrease in group $\mathrm{C}$ than in group $\mathrm{A}$ $(\mathrm{P}=0.023)$; however, the differences between groups $\mathrm{A}$ and $\mathrm{B}$, and between groups B and C, were not statistically significant ( $\mathrm{P}>0.05$ in both cases). The absence of interactions between groups and covariates was tested in all rank-based analyses of covariance, and was confirmed in all cases, except for the change in the number of sites with a PPD $\geq 6 \mathrm{~mm}(\mathrm{P}=0.028)$. Therefore, there was a significant interaction between groups and covariates in that case, which can be visualized in Fig. 2. In groups $\mathrm{A}$ and $\mathrm{B}$, when using a fixed baseline value for the number of sites with a PPD $\geq 6 \mathrm{~mm}$, the decrease in the number of sites with a PPD $\geq 6 \mathrm{~mm}$ after treatment was greater for smokers than for nonsmokers. Furthermore, that decrease 
Table IV. Changes in clinical characteristics between baseline and after three months, and the P-values for comparisons between groups (Kruskal-Wallis test).

\begin{tabular}{|c|c|c|c|c|c|}
\hline Characteristics & Group A & Group B & Group C & p1 & $\mathrm{p} 2$ \\
\hline$\Delta \mathrm{PPD}(\mathrm{mm})$ & $0.41 \pm 0.63$ & $0.57 \pm 0.54$ & $0.71 \pm 0.49$ & 0.117 & 0.753 \\
\hline$\triangle \mathrm{CAL}(\mathrm{mm})$ & $0.39 \pm 0.63$ & $0.55 \pm 0.47$ & $0.73 \pm 0.67$ & 0.135 & 0.282 \\
\hline$\triangle \mathrm{FMPS}(\%)$ & $16.64 \pm 19.11$ & $24.38 \pm 28.97$ & $8.81 \pm 26.18$ & 0.490 & 0.322 \\
\hline$\Delta \mathrm{FMBS}(\%)$ & $16.07 \pm 15.28$ & $19.31 \pm 24.21$ & $22.25 \pm 17.18$ & 0.537 & 0.769 \\
\hline$\Delta$ mean number of sites with PPD $6 \mathrm{~mm}$ & $8.14 \pm 12.87$ & $11.12 \pm 16.84$ & $15.94 \pm 11.74$ & 0.053 & $0.050^{\mathrm{a}}$ \\
\hline$\triangle \mathrm{PPD}$ of sites with $\mathrm{PPD} \geq 6 \mathrm{~mm}$ & $1.58 \pm 0.96$ & $1.78 \pm 0.98$ & $2.07 \pm 0.79$ & 0.321 & 0.518 \\
\hline$\triangle \mathrm{CAL}$ of sites with PPD $\geq 6 \mathrm{~mm}$ & $1.46 \pm 0.91$ & $1.64 \pm 1.05$ & $2.24 \pm 1.10$ & 0.164 & 0.313 \\
\hline
\end{tabular}

${ }^{\mathrm{a}} \mathrm{P}<0.05$ a significant correlation. p1, P-values corresponding to Kruskal-Wallis tests for comparisons between groups; $\mathrm{p} 2, \mathrm{P}$-values of tests for the group effect on $\triangle \mathrm{X}$ as determined by one-way rank-based ANCOVA, while controlling for baseline $\mathrm{X}$ and smoking. PPD, periodontal pocket depth; CAL, clinical attachment level; FMPS, full-mouth plaque score; FMBS, full-mouth bleeding score.

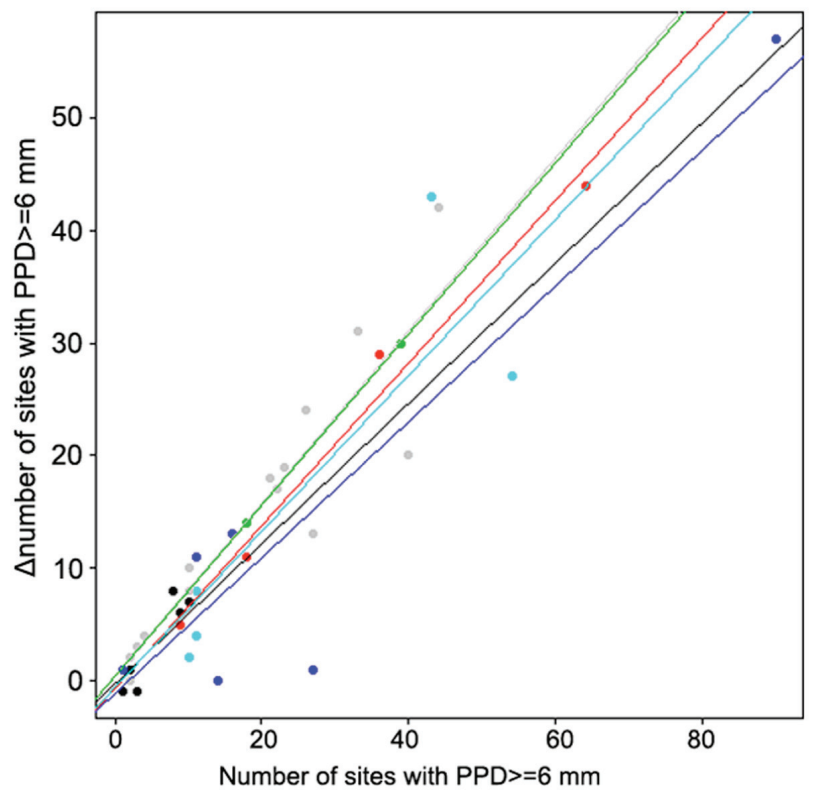

Figure 2. Scatterplot and regression lines showing the relation between the changes at three months in the number of sites with a PPD $\geq 6 \mathrm{~mm}$ and the baseline number of sites with a PPD $\geq 6 \mathrm{~mm}$ for group A, nonsmokers (black), smokers (red); group B, nonsmokers (blue), smokers (light blue); group C, nonsmokers (gray), smokers (green).

was more pronounced in group $\mathrm{C}$ than in the first two groups, which showed no significant difference between smokers and nonsmokers.

Changes in microbiological parameters. The detection scores for $\mathrm{Aa}, \mathrm{Pg}, \mathrm{Pi}, \mathrm{Tf}$ and $\mathrm{Td}$ at baseline were not significantly different among the different treatment groups $(\mathrm{P}>0.05$ for all species). In general, the detection scores for those pathogens remained stationary or decreased over time, with only a few exceptions, namely in the case of $A a$ (1 patient in group A and 1 patient in group B) and $P i$ (1 patient in group A and 1 patient in group B). The decreases in detection scores for $P g, T f$ and $T d$ in all three groups, and for $P i$ in groups $\mathrm{B}$ and $C$ were statistically significant. Significant differences among groups were found regarding changes that occurred in the detection frequency scores for $A a$ and $T f$ between baseline and the 3-month re-evaluation (Table VI). For Aa, Mann-Whitney tests showed differences between groups $\mathrm{A}$ and $\mathrm{C}(\mathrm{P}=0.048)$ and between groups $\mathrm{B}$ and $\mathrm{C}(\mathrm{P}=0.048)$, but not between groups $\mathrm{A}$ and $\mathrm{B}$; whereas for $T f$, groups $\mathrm{A}$ and $\mathrm{B}$ were found to be different from group $\mathrm{C}(\mathrm{P}<0.001$ in both cases), but not from each other $(\mathrm{P}=0.920)$ (Table $\mathrm{V})$.

Evaluation of bacterial resistance. A total of 69 bacterial isolates were identified in the bacterial cultures (average of 1.5 isolates per patient), and the isolates showed the following distribution pattern: Parvimonas micra $17.39 \%$, Prevotella intermedia 17.39\%, Actinomyces naeslundii $13.04 \%$, Peptoniphilus assacharolyticus 7.24\%, Porphyromonas gingivalis $5.79 \%$, Propionibacterium propionicus $4.34 \%$, Gemella morbillorum, Veillonella spp., Fusobacterium nucleatum, Prevotella bivia, Anaerococcus prevotii, Actinomyces israeli $2.89 \%$ each, and Bacteroides fragilis, Clostridium perfringens, Streptococcus parasanguinis, Streptococcus agalactiae, Peptostreptococcus anaerobius, Bacteroides ureolyticus, Actinomyces viscosus, Clostridium clostridioforme, Eubacterium limosum, Pseudomonas stutzeri, Peptostreptococcus anaerobius, Streptococcus oralis, Streptococcus mitis, Prevotella disiens, Bacteroides spp. below $2 \%$ each. The antimicrobial susceptibility (MIC range), percentage of susceptible, and the intermediate and resistant strains of the different species identified at baseline are presented in Table VI.

At the three-month reassessment, the total number of isolates was considerably reduced; however, 27 species could still be identified: Actinomyces naeslundii 22.22\%, Peptoniphilus assacharolyticus $14.81 \%$, Propionibecterium propionicus $11.11 \%$, Actinomyces israelii, Veillonella spp. and Prevotella intermedia $7.40 \%$ each. Parvimonas micra, Porphyromonas gingivalis, Gemella morbillorum, Clostridium perfringens, Prevotella bivia, Peptostreptococcus anaerobius, Eubacterium limosum, and Anaerococcus prevotii were less than $1.4 \%$ each. The antimicrobial susceptibility (MIC range), percentage of 'susceptible', 'intermediate' and 'resistant' strains of the different species identified at 3 months are presented in Table VII. 
Table V. Detection scores for the species $\mathrm{Aa}, \mathrm{Pg}, \mathrm{Pi}, \mathrm{Tf}, \mathrm{Td}$ at baseline and after 3 months in the three groups.

\begin{tabular}{|c|c|c|c|c|c|c|c|c|}
\hline \multirow[b]{2}{*}{ Species } & \multirow[b]{2}{*}{$\begin{array}{l}\text { Detection } \\
\text { score }\end{array}$} & \multicolumn{2}{|c|}{ Group A } & \multicolumn{2}{|c|}{ Group B } & \multicolumn{2}{|c|}{ Group C } & \multirow{2}{*}{$\begin{array}{l}\text { P-value } \\
\text { Kruskal- } \\
\text { Wallis test }\end{array}$} \\
\hline & & $\begin{array}{c}\text { Baseline } \\
\mathrm{n}(\%)\end{array}$ & $\begin{array}{c}3 \text { months } \\
\mathrm{n}(\%)\end{array}$ & $\begin{array}{c}\text { Baseline } \\
\mathrm{n}(\%)\end{array}$ & $\begin{array}{c}3 \text { months } \\
\mathrm{n}(\%)\end{array}$ & $\begin{array}{c}\text { Baseline } \\
\mathrm{n}(\%)\end{array}$ & $\begin{array}{c}3 \text { months } \\
\mathrm{n}(\%)\end{array}$ & \\
\hline \multirow[t]{6}{*}{$A a$} & 0 & $14(100)$ & $13(92.86)$ & 15 (93.75) & $15(93.75)$ & $12(75)$ & 15 (93.75) & $0.017^{\mathrm{a}}$ \\
\hline & 1 & - & - & $1(6.25)$ & - & - & $1(6.25)$ & \\
\hline & 2 & - & - & - & $1(6.25)$ & $1(6.25)$ & - & \\
\hline & 3 & - & $1(7.14)$ & - & - & $3(18.75)$ & - & \\
\hline & 4 & - & - & - & - & - & - & \\
\hline & $\begin{array}{l}\text { P-value } \\
\text { Wilcoxon tests } \\
\text { for intra-group } \\
\text { comparison }\end{array}$ & & & & & & & \\
\hline \multirow[t]{6}{*}{$P g$} & 0 & - & $3(21.43)$ & - & $4(25)$ & $2(12.5)$ & $13(81.25)$ & 0.155 \\
\hline & 1 & $12(85.71)$ & $11(78.57)$ & $12(75)$ & $12(75)$ & $13(81.25)$ & $3(18.75)$ & \\
\hline & 2 & $2(14.29)$ & - & $4(25)$ & - & $1(6.25)$ & - & \\
\hline & 3 & - & - & - & - & - & - & \\
\hline & 4 & - & - & - & - & - & - & \\
\hline & $\begin{array}{l}\text { P-value }^{\mathrm{b}} \\
\text { Wilcoxon tests } \\
\text { for intra-group } \\
\text { comparison }\end{array}$ & & & & & & $2^{\mathrm{a}}$ & \\
\hline \multirow[t]{6}{*}{$P i$} & 0 & $6(42.86)$ & $10(71.43)$ & $5(31.25)$ & $11(68.75)$ & $4(25)$ & $11(68.75)$ & 0.443 \\
\hline & 1 & $8(57.14)$ & $4(28.57)$ & $11(68.75)$ & $5(31.25)$ & $10(62.5)$ & $5(31.25)$ & \\
\hline & 2 & - & - & - & - & $2(12.5)$ & - & \\
\hline & 3 & - & - & - & - & - & - & \\
\hline & 4 & - & - & - & - & - & - & \\
\hline & $\begin{array}{l}\text { P-value }^{b} \\
\text { Wilcoxon tests } \\
\text { for intra-group } \\
\text { comparison }\end{array}$ & & & & & 0.0 & & \\
\hline \multirow[t]{6}{*}{$T f$} & 0 & - & $1(7.14)$ & - & $1(6.25)$ & $1(6.25)$ & $10(62.50)$ & $<0.001^{\mathrm{a}}$ \\
\hline & 1 & $4(28.57)$ & $7(50)$ & $5(31.25)$ & $7(43.75)$ & $5(31.25)$ & $6(37.50)$ & \\
\hline & 2 & $9(64.29)$ & $5(35.72)$ & $9(56.25)$ & $8(50)$ & $5(31.25)$ & - & \\
\hline & 3 & $1(7.14)$ & $1(7.14)$ & $2(12.5)$ & - & $5(31.25)$ & - & \\
\hline & 4 & - & - & - & - & - & - & \\
\hline & $\begin{array}{l}\text { P-value }^{\mathrm{b}} \\
\text { Wilcoxon tests } \\
\text { for intra-group } \\
\text { comparison }\end{array}$ & & & & & $<0$ & $01^{\mathrm{a}}$ & \\
\hline \multirow[t]{6}{*}{$T d$} & 0 & - & $7(50)$ & - & $8(50)$ & $2(12.5)$ & $14(87.5)$ & 0.344 \\
\hline & 1 & $14(100)$ & $7(50)$ & $15(93.75)$ & $8(50)$ & $14(87.5)$ & $2(12.5)$ & \\
\hline & 2 & - & - & $1(6.25)$ & - & - & - & \\
\hline & 3 & - & - & - & - & - & - & \\
\hline & 4 & - & - & - & - & - & - & \\
\hline & $\begin{array}{l}\text { P-value }^{\mathrm{b}} \\
\text { Wilcoxon tests } \\
\text { for intra-group } \\
\text { comparison }\end{array}$ & & & & & $<0$ & $01^{\mathrm{a}}$ & \\
\hline
\end{tabular}

${ }^{a}$ Denotes a statistically significant change; ${ }^{b}$ Wilcoxon tests for intra-group comparisons of pathogen detection scores at successive time-points, $\mathrm{P}<0.05$; 'Kruskal-Wallis tests for inter-group comparisons of differences between patients' initial and 3-month pathogen detection scores, $\mathrm{P}<0.05$. Aa, Aggregatibacter actinomycetemcomitans; Pg, Porphyromonas gingivalis; Pi, Prevotella intermedia; Tf, Tanererella forsythia; Td, Treponema denticola. Data are presented as n (\%). 
Table VI. Antimicrobial susceptibility of the periodontal isolates at baseline.

\begin{tabular}{|c|c|c|c|c|}
\hline \multirow[b]{2}{*}{ Microorganism and antibiotics } & \multirow[b]{2}{*}{ Range of MIC (mg/l) } & \multicolumn{3}{|c|}{$\%$} \\
\hline & & $\mathrm{S}$ & I & $\mathrm{R}$ \\
\hline \multicolumn{5}{|l|}{ Parvimonas micra $(\mathrm{N}=12)$} \\
\hline AMX & $\leq 0.047-0.125$ & 100 & 0 & 0 \\
\hline MTZ & $\leq 038-64$ & 58.3 & 0 & 41.6 \\
\hline \multicolumn{5}{|l|}{ Prevotella intermedia $(\mathrm{N}=12)$} \\
\hline AMX & $\leq 0.064-0.125$ & 100 & 0 & 0 \\
\hline MTZ & $\leq 0.5-3$ & 100 & 0 & 0 \\
\hline \multicolumn{5}{|l|}{ Actinomycens naeslundii $(\mathrm{N}=9)$} \\
\hline AMX & $\leq 0.023-0.125$ & 100 & 0 & 0 \\
\hline MTZ & $\leq 0.5-64$ & 55.6 & 0 & 44.4 \\
\hline \multicolumn{5}{|c|}{ Peptoniphilus assayarolyticus $(\mathrm{N}=5)$} \\
\hline AMX & $\leq 0.125-0.47$ & 100 & 0 & 0 \\
\hline MTZ & $\leq 1-4$ & 100 & 0 & 0 \\
\hline \multicolumn{5}{|l|}{ Porphyromonas gingivalis $(\mathrm{N}=4)$} \\
\hline AMX & $\leq 0.125-0.23$ & 100 & 0 & 0 \\
\hline MTZ & $\leq 0.5-1.5$ & 100 & 0 & 0 \\
\hline \multicolumn{5}{|c|}{ Propionibacterium propionicus $(\mathrm{N}=3)$} \\
\hline AMX & $\leq 0.125-0.19$ & 100 & 0 & 0 \\
\hline MTZ & $\leq 1-32$ & 66.6 & 0 & 33.3 \\
\hline \multicolumn{5}{|l|}{ Gemella morbillorum $(\mathrm{N}=2)$} \\
\hline AMX & $\leq 0.064-0.19$ & 100 & 0 & 0 \\
\hline MTZ & $\leq 1-32$ & 50 & 0 & 50 \\
\hline \multicolumn{5}{|l|}{ Veillonella $\mathrm{spp} .(\mathrm{N}=2)$} \\
\hline AMX & $\leq 0.064-0.125$ & 100 & 0 & 0 \\
\hline MTZ & $\leq 2-3$ & 100 & 0 & 0 \\
\hline \multicolumn{5}{|l|}{ Fusobacterium nucleatum $(\mathrm{N}=2)$} \\
\hline AMX & $\leq 0.125-0.5$ & 100 & 0 & 0 \\
\hline MTZ & $\leq 1.5-3$ & 100 & 0 & 0 \\
\hline \multicolumn{5}{|l|}{ Prevotella bivia $(\mathrm{N}=2)$} \\
\hline AMX & $\leq 0.125-0.19$ & 100 & 0 & 0 \\
\hline MTZ & 1 & 100 & 0 & 0 \\
\hline \multicolumn{5}{|l|}{ Anaerococcus prevotii $(\mathrm{N}=2)$} \\
\hline AMX & $\leq 0.064-0.125$ & 100 & 0 & 0 \\
\hline MTZ & $\leq 0.5-64$ & 50 & 0 & 0 \\
\hline \multicolumn{5}{|l|}{ Other $(\mathrm{N}=15)^{\mathrm{a}}$} \\
\hline AMX & $\leq 0.047-0.5$ & 100 & 0 & 0 \\
\hline MTZ & $\leq 0.5-32$ & 93.3 & 0 & 6.6 \\
\hline
\end{tabular}

${ }^{a}$ Bacteroides fragilis, Clostridium perfringens, Streptococcus parasanguinis, Streptococcus agalactiae, Peptostreptococcus anaerobius, Bacteroides ureolyticus, Actinomyces viscosus, Clostridium clostridioforme, Eubacterium limosum, Pseudomonas stutzeri, Peptostreptococcus anaerobius, Streptococcus oralis, Streptococcus mitis, Prevotella disiens and Bacteroides spp. MIC, minimal inhibitory concentration; AMX, amoxicillin; MTZ, metronidazole; S, susceptible; I, intermediate; R, resistant.

There was no resistance to AMX prior to treatment; however, after treatment, one strain of Actinomyces israelii (group A) and one strain of Anareroccocus prevotii (group C) were found to be resistant. The latter strain was identified in the same patient in group $\mathrm{C}$, and was classified as being antibiotic sensitive prior to treatment, but later became resistant to both AMX and MTZ.

Resistance to MTZ prior to treatment was identified in a total of 13 strains ( 5 in group A, 5 in group B and 3 in group C): 5 strains of Parvimonas micra (1 in group A, 2 in 
TableVII. Antimicrobial susceptibility of the periodontal isolates at the 3-month re-evaluation.

\begin{tabular}{|c|c|c|c|c|}
\hline \multirow[b]{2}{*}{ Microorganism and antibiotics } & \multirow[b]{2}{*}{ Range of MIC (mg/l) } & \multicolumn{3}{|c|}{$\%$} \\
\hline & & $\mathrm{S}$ & I & $\mathrm{R}$ \\
\hline \multicolumn{5}{|l|}{ Actinomyces naeslundii $(\mathrm{N}=6)$} \\
\hline AMX & $\leq 0.064-0.5$ & 100 & 0 & 0 \\
\hline MTZ & $\leq 0.5-1$ & 100 & 0 & 0 \\
\hline \multicolumn{5}{|c|}{ Peptoniphilus assacharolyticus $\mathrm{N}=(4)$} \\
\hline AMX & 0.125 & 100 & 0 & 0 \\
\hline MTZ & $\leq 1-4$ & 100 & 0 & 0 \\
\hline \multicolumn{5}{|c|}{ Propionibacterium propionicus $(\mathrm{N}=3)$} \\
\hline AMX & $\leq 0.032-0.125$ & 100 & 0 & 0 \\
\hline MTZ & $\leq 1.5-32$ & 100 & 0 & 0 \\
\hline \multicolumn{5}{|l|}{ Actinomyces israelli $(\mathrm{N}=2)$} \\
\hline AMX & $\leq 0.125-4$ & 50 & 0 & 50 \\
\hline MTZ & $\leq 1-4$ & 100 & 0 & 0 \\
\hline \multicolumn{5}{|l|}{ Veillonella spp. $(\mathrm{N}=2)$} \\
\hline AMX & $\leq 0.032-0.12$ & 100 & 0 & 0 \\
\hline MTZ & 1.5 & 100 & 0 & 0 \\
\hline \multicolumn{5}{|l|}{ Prevotella intermedia $(\mathrm{N}=2)$} \\
\hline AMX & 0.125 & 100 & 0 & 0 \\
\hline MTZ & $\leq 4-32$ & 50 & 0 & 50 \\
\hline \multicolumn{5}{|l|}{ Other $(\mathrm{N}=8)^{\mathrm{a}}$} \\
\hline Amoxicillin & $\leq 0.032-6$ & 87.5 & 0 & 12.5 \\
\hline Metronidazole & $\leq 2-64$ & 87.5 & & 12.5 \\
\hline
\end{tabular}

${ }^{\text {a }}$ Parvimonas micra, Porphyromonas gingivalis, Gemella morbillorum, Clostridium perfringens, Prevotella bivia, Peptostreptococcus anaerobius, Eubacterium limosum and Anaerococcus prevotii. MIC, minimal inhibitory concentration; AMX, amoxicillin; MTZ, metronidazole; $\mathrm{S}$, susceptible; I, intermediate; R, resistant.

Table VIII. Intra-group comparisons of the oxidative stress values before and after treatment, and the P-values of differences (Wilcoxon tests).

\begin{tabular}{lcrrr}
\hline Oxidative stress characteristics & Study group & Baseline & 3-months re-evaluation & P-value \\
\hline d-ROMs (Carratelli units) & A & $499.50 \pm 114.24$ & $498.40 \pm 126.84$ & 0.903 \\
& B & $523.60 \pm 127.75$ & $495.70 \pm 109.99$ & 0.130 \\
BAP $(\mu \mathrm{mol} / \mathrm{l})$ & C & $550.40 \pm 139.73$ & $429.60 \pm 127.09$ & $<0.001^{\text {a }}$ \\
& A & $1839 \pm 480.49$ & $1879 \pm 527.45$ & 0.903 \\
& B & $1853 \pm 473.36$ & $1814 \pm 482.59$ & 0.597 \\
& C & $1995 \pm 688.54$ & $2072 \pm 509.07$ & 0.117
\end{tabular}

Values are presented as the mean \pm SD. d-ROM, derivatives of reactive oxygen metabolites; BAP, biological antioxidant potential. ${ }^{\text {a Denotes a }}$ statistically significant change.

group B, 2 in group C), 4 of Actinomyces naeslundii (3 in group A and 1 in group B), 1 of Bacteriodes spp. (group A), 1 of Gemella morbillorum (group B), 1 of Propionibacterium propionicum (group B), and 1 of Anerococcus prevotii (group C).

Resistance to MTZ after treatment was found in one strain of $P i$ (group A) and one strain Anareroccocus prevotii (group C).
Changes in oxidative stress balance. There was a statistically significant decrease in the mean d-ROM values in group C, when compared with the mean baseline values (Table VIII).

There were also significant differences between groups with respect to changes in d-ROM values (Table IX). The decreases in mean d-ROM values in group $\mathrm{C}$ were significantly greater than those in groups $\mathrm{A}(\mathrm{P}=0.012)$ and $\mathrm{B}(\mathrm{P}=0.025)$; however, there was no difference between groups $\mathrm{A}$ and $\mathrm{B}(\mathrm{P}=0.525)$. 
Table IX. Changes in oxidative stress characteristics between baseline and the 3-month re-evaluation.

\begin{tabular}{lccccc}
\hline Oxidative stress characteristics & Group A & Group B & Group C & p1 & p2 \\
\hline$\Delta$ d-ROM & $1.08 \pm 130.19$ & $27.88 \pm 115.56$ & $120.80 \pm 89.03$ & $0.009^{\mathrm{a}}$ & 0.018 \\
$\Delta$ BAP & $-40.64 \pm 847.33$ & $39.17 \pm 699.87$ & $-76.54 \pm 931.86$ & 0.394 & 0.231 \\
\hline
\end{tabular}

P-values for differences between groups. p1, P-values corresponding to Kruskal-Wallis tests; $\mathrm{p} 2$, P-values of tests for the group effect on $\Delta \mathrm{X}$ as determined by rank-based ANCOVA, while controlling for baseline X and smoking). d-ROM, derivatives of reactive oxygen metabolites; BAP, biological antioxidant potential. ${ }^{a}$ Denotes a statistically significant change.

Significant positive linear associations were found only in group $\mathrm{C}$, and those occurred between changes in d-ROM values and the number of sites with a PPD $\geq 6 \mathrm{~mm}$. Negative linear associations were found between d-ROM changes and changes in FMPS.

\section{Discussion}

To the best of our knowledge, this is the first study to investigate the clinical and microbiological effects of two different regimens of systemic antibiotic therapy given adjunctive to non-surgical periodontal therapy in patients with periodontitis. Moreover, this study also investigated changes that occurred in systemic oxidative stress markers and the resistance of main periopathogens. Unlike recent studies that only focused on clinical changes in moderate and deep pockets $(4,30)$, our study also considered the mean full-mouth PPD as an endpoint.

As expected, the mean values for clinical parameters significantly improved in the intra-group comparisons, with the interesting exception of FMPS, for which the mean values significantly decreased in groups $\mathrm{A}$ and $\mathrm{B}$, but not in group C. No explanation could be found for this outcome in the context of the better clinical outcomes in group $\mathrm{C}$ at three months. The mean value for intra-group full-mouth PPD reduction significantly decreased in group $\mathrm{B}$ between baseline $(3.71 \pm 0.77 \mathrm{~mm})$ and 3 months $(3.14 \pm 0.820 \mathrm{~mm}, \mathrm{P}=0.02)$, and also in group $\mathrm{C}$ from baseline $(3.75 \pm 0.86 \mathrm{~mm})$ to 3 months (3.04 $\pm 0.71 \mathrm{~mm}, \mathrm{P}<0.001)$. These results showed that both antibiotic regimens exhibited better clinical efficacy than that obtained by using SRP alone, and are similar to results from other studies that chose mean full-mouth PPD or CAL as the primary outcome $(13,20,24,25,62)$ to evaluate the efficacy of various antibiotic regimens. Intra-group comparisons showed that the mean CAL value significantly improved in all three groups, and while inter-group comparisons showed more pronounced improvements in group $\mathrm{C}$, the differences were not statistically significant. These results are in line to those obtained by Carvalho et al (3), who used a treatment regimen of SRP + MTZ (400 mg TID for 10 days) and by Matarazzo et al (20), who treated patients with SRP + AMX $(500 \mathrm{mg})+$ MTZ (400 mg) for 14 days.

An analysis of pockets $\geq 6 \mathrm{~mm}$ in depth, which are known to harbour biofilm that is more difficult to reached with mechanical instrumentation, was performed in our study in the context of the antibiotic systemic medication given adjunctive to SRP (12). The use of antibiotics for 7 days significantly reduced the number of sites with a $\mathrm{PD} \geq 6 \mathrm{~mm}$, when compared with the placebo group $(\mathrm{P}=0.023)$. No statistically significant difference was found between groups $\mathrm{A}$ and $\mathrm{B}$ or between groups $\mathrm{B}$ and $\mathrm{C}$.

Regarding the smoking status of the patients, in both groups $\mathrm{A}$ and $\mathrm{B}$, the decrease in the number of sites with $\mathrm{PPD} \geq 6 \mathrm{~mm}$ was greater for smokers than for nonsmokers. This can be partially explained by the fact that the smokers had more sites with PPD $\geq 6 \mathrm{~mm}$ at baseline than did the non-smokers. The decrease was most pronounced in group C, where there was no difference between the smokers and nonsmokers; however, given the small sample size and the small number of smokers in each group, this result should be interpreted with caution.

When prescribing a systemic antibiotic regimen for periodontal infection, the issues of antibiotic resistant species being present prior to treatment and the possible creation of antibiotic resistant species are of particular importance. When prescribing antibiotics, practitioners have considered the chance for side effects, the possibility of bacterial resistance, as well as the chance of success when using the recommended dose of antibiotics (63). However, several studies demonstrated that systemically administered antibiotics resulted in transitory selection of subgingival bacterial strains resistant to tetracycline (64), doxycycline (DOX) $(65,66)$, AMX and MTZ (36). DOX-resistant baseline isolates were reported in $12 \%$ of the total counts by Walker (67), $0.90 \%$ by Fiehn and Westergaard (65), and $6 \%$ by Feres et al (66).

No bacterial strains resistant to AMX were identified at baseline; however, 13 strains were resistant to MTZ at baseline. These resistant strains constituted $18 \%$ of the total strains, and were present in all the treatment groups, even though none of the patients had received antibiotics in the previous 6 months, and the patients who harbored the resistant isolates did not recall having previously taken MTZ. In a similar study with 48 patients, bacterial species were identified in cultures, and the five most common morphotypes were analyzed by PCR (37). Antibiotic susceptibility was determined by the E-test ${ }^{\circledR}$, which was also used in this study. Among 261 identified isolates, the investigators found that the $S$. viridans resistance rates for AMX, clindamycin, and tetracycline were 0, 10 and 9-22\%, respectively. As for azithromycin, the resistance rates ranged from $18.2 \%$ for S. sanguis to $47.7 \%$ for S. mitis. Prevotella isolates were susceptible to AMX-clavulanic acid, but showed AMX resistance rates of $17.1 \%$ for P. buccae and $26.3 \%$ for P. denticola. Less than $6 \%$ of all Prevotella species were resistant to MTZ, while $21.1 \%$ were resistant to clindamycin. In this study, the highest resistance rates prior to therapy were found 
for P. micra (7.24\%) and A. naeslundii (5.79\%). Moreover, in the present study, the data confirmed that there was no resistance to AMX prior to therapy. Similar results (no resistance to AMX prior to therapy) were also found by Herrera et al (68) and Ardila et al (69); however, those investigators found strains that were resistant to azithromycin (68) and clindamycin (69).

The evolution of antibiotic resistance in this study is similar to that reported in a study conducted with 20 patients who were taking systemic DOX (100 mg/day) for 14 days (66). Despite an increase in resistance detected during the treatment phase of that study (from $6 \pm 2$ to $48 \pm 9 \%$ ), those investigators found that the resistance decreased to $25 \pm 6 \% 2$ weeks later, and to $9 \pm 2 \%$ at 90 days post-treatment. Similar results were obtained by Fiehn and Westergaard (65), who found that the percentage of organisms resistant to $10 \mu \mathrm{g} / \mathrm{ml}$ DOX increased from a baseline level of 0.9 to $18.5 \%$ one week after completion of a 3 -week treatment regimen, and then subsequently returned to baseline levels at $\sim 15$ weeks. In a later study, resistant species were identified in subgingival and saliva samples obtained from patients with chronic periodontitis being treated with SRP and adjuvant antibiotic therapy (AMX or MTZ) (36). That study enrolled 20 patients who had undergone clinical and microbiological assessments and were randomly assigned to two groups: AMX $500 \mathrm{mg}$, TID x 14 days or MTZ $250 \mathrm{mg}$, TID $x 14$ days. It was found that the resistant isolates detected during or after therapy had also been detected prior to therapy. The most common resistant species in the MTZ group were A. naeslundii, S. constellatus, S. mitis, S. oralis, A. odontolyticus, and S. sanguis, and in AMX treatment group were S. constellatus, $P$. nigrescens, E. saburreum, A. naeslundii, $S$. oralis, $P$. melaninogenica, and $P$. intermedia. While treatment with systemic antibiotics gradually increased the percentage of resistant subgingival species, a major component of the subgingival plaque remained sensitive to antibiotics during their administration. However, the antibiotic resistant isolates returned to their baseline levels after 90 days. Other strains identified in this study with antibiotic resistance prior to therapy were P. micra, Bacteroides spp., Gemella morbillorum, Propionibacterium propionicum and Anerococcus prevotii.

In an in vitro study, Rams et al (33) found that $30.3 \%$ of bacterial strains were resistant to MTZ prior to therapy. In another study, van Winkelhoff et al (34) evaluated the antibiotic resistance of $A a$ in 118 patients with localized, generalized, and refractory periodontitis. Similar to this study, significant reductions in PPD and increases in CAL were obtained in almost all patients. Four patients remained positive for $A a$ after therapy. MTZ resistance was observed in two out of four strains in those patients. In this study, we similarly found a greater percentage of MTZ-resistant isolates prior to therapy (18.84\%) than after 3 months of therapy $(7.40 \%)$.

Data from the literature attest that periodontitis patients are more susceptible to an imbalance in oxidative-antioxidant processes when compared with healthy subjects $(48,49)$, and periodontal therapy can have a beneficial effect on both clinical and biochemical parameters. High levels of oxidative species are usually found in subjects with risk factors such as cigarette smoking, alcohol abuse, an unbalanced diet, or who have diseases associated with changes in oxidative balance, such as cardiovascular diseases, metabolic diseases, neurodegenerative diseases, autoimmune rheumatic diseases (rheumatoid arthritis, systemic lupus erythematosus), skin diseases like psoriasis, and periodontitis (70,71). A reduction in BAP suggests a direct correlation with reduced activity of the plasmatic antioxidant barrier. This is often seen in elderly people (72) who are undergoing hemodialysis (73) and in patients with metabolic syndrome (74), but may not always correlate with an inflammatory periodontal status $(75,76)$. In the present study, there were significant differences between groups with respect to changes in d-ROM values [a significantly greater decrease in $\mathrm{d}$-ROMs values in group $\mathrm{C}$ when compared to the changes in group $\mathrm{A}(\mathrm{P}=0.012)$ and group $\mathrm{B}(\mathrm{P}=0.025)]$. These results were similar to those obtained by Tamaki et al (71), who showed that non-surgical periodontal treatment improved both periodontal clinical parameters and plasma d-ROMs values at a 2-month reassessment. This suggests a close relationship between periodontal conditions and systemic oxidative status. Moreover, a trend of reduction in d-ROM levels as measured at 1 month after therapy was observed in a study conducted by D'Aiuto et al (77). In this study, BAP levels were not significantly correlated with periodontal parameters, and this was similar to results reported by Tamaki et al (75) and Machida et al (76).

One limitation of the present study is the small number of patients we investigated. The fact that the three groups were not homogeneous with respect to PPD and CAL at baseline could also represent a potential limitation. However, in our analysis of changes that occurred between appointments, this deficiency was handled by adjusting for the baseline values of the parameters, while testing for group effects in the analysis of covariance. Furthermore, the fact that one strain of Anaeroccocus prevotii was identified in the same patient as being antibiotic sensitive prior to treatment, and then became resistant to both AMX and MTZ after 7 days, suggests that certain strains can acquire bacterial resistance during systemic antibiotic therapy.

From a clinical point of view, our microbiologic and oxidative stress data suggest that a 7-day systemic antibiotic regimen remains the regimen of choice as an adjuvant to SRP, both in smokers and non-smokers. Further studies with larger groups of patients and longer follow-up times, possibly based on new fundamental integrative investigation methods (e.g. cellomics, which integrates genomics and proteomics of diseased tissues) (78) will offer a new insight in understanding the complex interactions that the periodontal pathogens undergo with the host, both in the health, disease and during systemic antimicrobial treatments (79). A future direction could also focus on the in vitro resistance of bacterial species interacting with periodontal cells grown on materials biocompatible with the oral environment (80). More clinical studies are needed, as well, to fully evaluate the evolution of parameters and variables associated with periodontal inflammation, and their correlation over time during different antibiotic treatment regimens.

In conclusion, within the limitations of this study, it can be concluded that non-surgical periodontal therapy given in combination with a 7-day course of antibiotics proved more effective for improving clinical parameters when compared with a 3-day course of antibiotics. The detection of several pathogenic bacteria ( $A a$ and $T d$ ) showed greater improvement with the 7-day antibiotic regimen, as well as the systemic oxidative 
stress markers (decrease in d-ROMs). Bacterial resistance was found in fewer strains after treatment than prior to treatment.

\section{Acknowledgements}

The authors thank Dr Octavia Vela and Dr Viorelia Rădulescu for their assistance with patient management. We also thank Ms. Claudia Zaharia for her kind assistance with statistical processing of the data.

\section{Funding}

This study was supported by internal funds from 'Victor Babeş' University of Medicine and Pharmacy, Timişoara, Romania: Doctoral Grant no. 13901/19.11.2014.

\section{Availability of data and materials}

The datasets used/analyzed during the current study are available from the corresponding author on reasonable request.

\section{Authors' contributions}

SB, FB, MB and SIS participated in study design, sample collection, and data acquisition. SB, MB and SIS drafted the manuscript and critically revised it for intellectual content. DR, AA, DM, CB, FH and ERB contributed to data acquisition. SB and FB contributed equally to this study, and can therefore be regarded as first authors. All authors read and approved the final version of the manuscript.

\section{Ethics approval and consent to participate}

The study protocol was approved by the Research Ethics Committee of the 'Victor Babeş' University of Medicine and Pharmacy (approval no. 06/07.05.2018). All subjects were informed about the nature and purpose of the study, and each subject signed an informed consent document giving permission for the dental procedures and sampling of biological material.

\section{Patient consent for publication}

Not applicable.

\section{Competing interests}

The authors declare that they have no competing interests.

\section{References}

1. Egelberg J: Periodontics the Scientific Way, Synopses of Clinical Studies. Vol 1. 3rd edition. Odonto Science, Malmo, p12, 1999.

2. Cugini MA, Haffajee AD, Smith C, Kent RL Jr and Socransky SS: The effect of scaling and root planing on the clinical and microbiological parameters of periodontal diseases: 12-month results. J Clin Periodontol 27: 30-36, 2000.

3. Carvalho LH, D'Avila GB, Leão A, Haffajee AD, Socransky SS and Feres M: Scaling and root planing, systemic metronidazole and professional plaque removal in the treatment of chronic periodontitis in a Brazilian population. I. Clinical results. J Clin Periodontol 31: 1070-1076, 2004.
4. Cosgarea R, Juncar R, Heumann C, Tristiu R, Lascu L, Arweiler N, Stavropoulos A and Sculean A: Non-surgical periodontal treatment in conjunction with 3 or 7 days systemic administration of amoxicillin and metronidazole in severe chronic periodontitis patients. A placebo-controlled randomized clinical study. J Clin Periodontol 43: 767-777, 2016

5. Renvert S, Wikström M, Dahlén G, Slots J and Egelberg J: Effect of root debridement on the elimination of Actinobacillus actinomycetemcomitans and Bacteroides gingivalis from periodontal pockets. J Clin Periodontol 17: 345-350, 1990.

6. Mombelli A, Gmür R, Gobbi C and Lang NP: Actinobacillus actinomycetemcomitans in adult periodontitis. I. Topographic distribution before and after treatment. J Periodontol 65: 820-826, 1994.

7. Marsh PD: Dental plaque: Biological significance of a biofilm and community life-style. J Clin Periodontol 32 (Suppl 6): 7-15, 2005.

8. van Winkelhoff AJ, Rodenburg JP, Goené RJ, Abbas F, Winkel EG and de Graaff J: Metronidazole plus amoxycillin in the treatment of Actinobacillus actinomycetemcomitans associated periodontitis. J Clin Periodontol 16: 128-131, 1989.

9. Pavicić MJ, van Winkelhoff AJ, Douqué NH, Steures RW and de Graaff J: Microbiological and clinical effects of metronidazole and amoxicillin in Actinobacillus actinomycetemcomitans-associated periodontitis. A 2-year evaluation. J Clin Periodontol 21: 107-112, 1994.

10. Flemmig TF, Milián E, Karch H and Klaiber B: Differential clinical treatment outcome after systemic metronidazole and amoxicillin in patients harboring Actinobacillus actinomycetemcomitans and/or Porphyromonas gingivalis. J Clin Periodontol 25: 380-387, 1998.

11. Goutoudi P, Diza E and Arvanitidou M: Effect of periodontal therapy on crevicular fluid interleukin-1beta and interleukin-10 levels in chronic periodontitis. J Dent 32: 511-520, 2004.

12. Guerrero A, Griffiths GS, Nibali L, Suvan J, Moles DR, Laurell L and Tonetti MS: Adjunctive benefits of systemic amoxicillin and metronidazole in non-surgical treatment of generalized aggressive periodontitis: A randomized placebo-controlled clinical trial. J Clin Periodontol 32: 1096-1107, 2005.

13. Ehmke B, Moter A, Beikler T, Milian E and Flemmig TF: Adjunctive antimicrobial therapy of periodontitis: Long-term effects on disease progression and oral colonization. J Periodontol 76: 749-759, 2005.

14. Cionca N, Giannopoulou C, Ugolotti G and Mombelli A: Amoxicillin and metronidazole as an adjunct to full-mouth scaling and root planing of chronic periodontitis. J Periodontol 80: 364-371, 2009.

15. Cionca N, Giannopoulou C, Ugolotti G and Mombelli A: Microbiologic testing and outcomes of full-mouth scaling and root planing with or without amoxicillin/metronidazole in chronic periodontitis. J Periodontol 81: 15-23, 2010.

16. Ribeiro EP, Bittencourt S, Zanin IC, Bovi Ambrosano GM, Sallum EA, Nociti FH Jr, Gonçalves RB and Casati MZ: Full-mouth ultrasonic debridement associated with amoxicillin and metronidazole in the treatment of severe chronic periodontitis. J Periodontol 80: 1254-1264, 2009.

17. Yek EC, Cintan S, Topcuoglu N, Kulekci G, Issever H and Kantarci A: Efficacy of amoxicillin and metronidazole combination for the management of generalized aggressive periodontitis. J Periodontol 81: 964-974, 2010.

18. Rodrigues AS, Lourenção DS, Lima Neto LG, Pannuti CM, Hirata RD, Hirata MH, Lotufo RF and De Micheli G: Clinical and microbiologic evaluation, by real-time polymerase chain reaction, of non-surgical treatment of aggressive periodontitis associated with amoxicillin and metronidazole. J Periodontol 83: 744-752, 2012.

19. Rooney J, Wade WG, Sprague SV, Newcombe RG and Addy M: Adjunctive effects to non-surgical periodontal therapy of systemic metronidazole and amoxycillin alone and combined. A placebo controlled study. J Clin Periodontol 29: 342-350, 2002.

20. Matarazzo F, Figueiredo LC, Cruz SE, Faveri M and Feres M: Clinical and microbiological benefits of systemic metronidazole and amoxicillin in the treatment of smokers with chronic periodontitis: A randomized placebo-controlled study. J Clin Periodontol 35: 885-896, 2008.

21. Mestnik MJ, Feres M, Figueiredo LC, Duarte PM, Lira EA and Faveri M: Short-term benefits of the adjunctive use of metronidazole plus amoxicillin in the microbial profile and in the clinical parameters of subjects with generalized aggressive periodontitis. J Clin Periodontol 37: 353-365, 2010. 
22. MestnikMJ,Feres M,FigueiredoLC,SoaresG,Teles RP,FermianoD, Duarte PM and Faveri M: The effects of adjunctive metronidazole plus amoxicillin in the treatment of generalized aggressive periodontitis: A 1-year double-blinded, placebo-controlled, randomized clinical trial. J Clin Periodontol 39: 955-961, 2012.

23. Heller D, Varela VM, Silva-Senem MX, Torres MC, Feres-Filho EJ and Colombo AP: Impact of systemic antimicrobials combined with anti-infective mechanical debridement on the microbiota of generalized aggressive periodontitis: A 6-month RCT. J Clin Periodontol 38: 355-364, 2011.

24. Silva MP, Feres M, Sirotto TA, Soares GM, Mendes JA Faveri $\mathrm{M}$ and Figueiredo LC: Clinical and microbiological benefits of metronidazole alone or with amoxicillin as adjuncts in the treatment of chronic periodontitis: A randomized placebocontrolled clinical trial. J Clin Periodontol 38: 828-837, 2011

25. Feres M, Soares GM, Mendes JA, Silva MP, Faveri M, Teles R, Socransky SS and Figueiredo LC: Metronidazole alone or with amoxicillin as adjuncts to non-surgical treatment of chronic periodontitis: A 1-year double-blinded, placebo-controlled, randomized clinical trial. J Clin Periodontol 39: 1149-1158, 2012

26. Griffiths GS, Ayob R, Guerrero A, Nibali L, Suvan J, Moles DR and Tonetti MS: Amoxicillin and metronidazole as an adjunctive treatment in generalized aggressive periodontitis at initial therapy or re-treatment: A randomized controlled clinical trial. J Clin Periodontol 38: 43-49, 2011.

27. Jorgensen MG and Slots J: Responsible use of antimicrobials in periodontics. J Calif Dent Assoc 28: 185-193, 2000.

28. Newman MG, Tkei HH, Klokkevold PR and Carranza FA: Newman and Carranza's Clinical Periodontology. Vol. 1. 13th edition. Elsevier, Amsterdam, 2019.

29. Vogelman B and Craig WA: Kinetics of antimicrobial activity. J Pediatr 108: 835-840, 1986

30. Cosgarea R, Heumann C, Juncar R, Tristiu R, Lascu L, Salvi GE, Arweiler NB and Sculean A: One year results of a randomized controlled clinical study evaluating the effects of non-surgical periodontal therapy of chronic periodontitis in conjunction with three or seven days systemic administration of amoxicillin/metronidazole. PLoS One 12: e0179592, 2017.

31. Laxminarayan R, Duse A, Wattal C, Zaidi AK, Wertheim HF Sumpradit N, Vlieghe E, Hara GL, Gould IM, Goossens H, et al: Antibiotic resistance-the need for global solutions. Lancet Infect Dis 13: 1057-1098, 2013.

32. Mah MW and Memish ZA: Antibiotic resistance. An impending crisis. Saudi Med J 21: 1125-1129, 2000.

33. Rams TE, Degener JE and van Winkelhoff AJ: Antibiotic resistance in human chronic periodontitis microbiota. J Periodontol 85: $160-169,2014$.

34. van Winkelhoff AJ, Tijhof CJ and de Graaff J: Microbiological and clinical results of metronidazole plus amoxicillin therapy in Actinobacillus actinomycetemcomitans-associated periodontitis. J Periodontol 63: 52-57, 1992.

35. van Winkelhoff AJ,Herrera D, Oteo A and Sanz M: Antimicrobial profiles of periodontal pathogens isolated from periodontitis patients in The Netherlands and Spain. J Clin Periodontol 32: 893-898, 2005

36. Feres M, Haffajee AD, Allard K, Som S, Goodson JM and Socransky SS: Antibiotic resistance of subgingival species during and after antibiotic therapy. J Clin Periodontol 29: 724-735, 2002.

37. Maestre JR, Bascones A, Sánchez P, Matesanz P, Aguilar L, Giménez MJ, Pérez-Balcabao I, Granizo JJ and Prieto J: Odontogenic bacteria in periodontal disease and resistance patterns to common antibiotics used as treatment and prophylaxis in odontology in Spain. Rev Esp Quimioter 20: 61-67, 2007.

38. Lakhssassi N, Elhajoui N, Lodter JP, Pineill JL and Sixou M Antimicrobial susceptibility variation of 50 anaerobic periopathogens in aggressive periodontitis: An interindividual variability study. Oral Microbiol Immunol 20: 244-252, 2005.

39. Dehelean CA, Soica C, Pinzaru I, Coricovac D, Danciu C Pavel I, Borcan F, Spandidos DA, Tsatsakis AM and Baderca F: Sex differences and pathology status correlated to the toxicity of some common carcinogens in experimental skin carcinoma. Food Chem Toxicol 95: 149-158, 2016.

40. Pricop R, Cristea VC, Gheorghe I, Tatu AL, Mihaescu G and Chifiriuc MC: Matrix-assisted laser desorption/ionization time-of-flight mas spectrometry (MALDI-TOF MS) reveals the anaerobic Slakia exigua as unique etiology of a dental abscess. Biointerface Res Appl Chem 7: 1995-1997, 2017.

41. Oktay S, Chukkapalli SS, Rivera-Kweh MF, Velsko IM, Holliday LS and Kesavalu L: Periodontitis in rats induces systemic oxidative stress that is controlled by bone-targeted antiresorptives. J Periodontol 86: 137-145, 2015.
42. Căruntu C, Boda D, Musat S, Căruntu A and Mandache E: Stress-induced mast cell activation in glabrous and hairy skin. Mediators Inflamm 2014: 105950, 2014.

43. Dahiya P, Kamal R, Gupta R, Bhardwaj R, Chaudhary K and Kaur S: Reactive oxygen species in periodontitis. J Indian Soc Periodontol 17: 411-416, 2013.

44. Robinson JM: Reactive oxygen species in phagocytic leukocytes. Histochem Cell Biol 130: 281-297, 2008.

45. Tóthová L and Celec P: Oxidative stress and antioxidants in the diagnosis and therapy of periodontitis. Front Physiol 8: 1055, 2017

46. Tsai CC, Chen HS, Chen SL, Ho YP, Ho KY, Wu YM and Hung CC: Lipid peroxidation: A possible role in the induction and progression of chronic periodontitis. J Periodontal Res 40: 378-384, 2005

47. Konopka T, Król K, Kopeć W and Gerber H: Total antioxidant status and 8-hydroxy-2'-deoxyguanosine levels in gingival and peripheral blood of periodontitis patients. Arch Immunol Ther Exp (Warsz) 55: 417-422, 2007.

48. Akalin FA, Baltacioğlu E, Alver A and Karabulut E: Lipid peroxidation levels and total oxidant status in serum, saliva and gingival crevicular fluid in patients with chronic periodontitis. J Clin Periodontol 34: 558-565, 2007.

49. Chapple IL, Brock GR, Milward MR, Ling N and Matthews JB: Compromised GCF total antioxidant capacity in periodontitis: Cause or effect? J Clin Periodontol 34: 103-110, 2007.

50. Armitage GC: Development of a classification system for periodontal diseases and conditions. Ann Periodontol 4: 1-6, 1999.

51. Tonetti MS, Pini-Prato G and Cortellini P: Effect of cigarette smoking on periodontal healing following GTR in infrabony defects. A preliminary retrospective study. J Clin Periodontol 22: 229-234, 1995

52. Miller PD Jr: A classification of marginal tissue recession. Int $\mathrm{J}$ Periodontics Restorative Dent 5: 8-13, 1985.

53. Hamp SE, Nyman S and Lindhe J: Periodontal treatment of multirooted teeth. Results after 5 years. J Clin Periodontol 2: 126-135, 1975 .

54. Quirynen M, Bollen CML, Vandekerckhove BN, Dekeyser C, Papaioannou W and Eyssen H: Full- vs. partial-mouth disinfection in the treatment of periodontal infections: Short-term clinical and microbiological observations. J Dent Res 74: 1459-1467, 1995

55. Slots J: Selective medium for isolation of Actinobacillus actinomycetemcomitans. J Clin Microbiol 15: 606-609, 1982.

56. Tatu AL, Merezeanu N, Pântea O, Gheorghe I, Popa M, Banu O, Cristea VC, Chifiriuc MC, Lazăr V and Marutescu L: Resistance features of Pseudomonas aeruginosa strains isolated from patients with infectious complications of cardiovascular surgery. Biointerface Res Appl Chem 7: 2004-2008, 2017.

57. Gheorghe I, Tatu AL, Lupu I, Thamer O, Cotar AI, Pircalabioru GG, Popa M, Cristea VC, Lazar V and Chifiriuc MC: Molecular characterization of virulence and resistance features in Staphylococcus aureus clinical strains isolated from cutaneous lesions in patients with drug adverse reactions. Rom Biotechnol Lett 22: 12321-12327, 2017.

58. R Core Team: A language and Environment for Statistical Computing. Foundation for Statistical Computing, Vienna, p201, 2017.

59. Gamer M, Lemon J, Fellows I and Singh P: irr: Various Coefficients of Interrater Reliability and Agreement. R package version $0.84 .1,2019$

60. Hettmansperger TP and McKean JW: Robust nonparametric statistical methods. Vol. 1. 2nd edition. Chapman \& Hall, Boca Raton, FL, 2011.

61. Kloke J and McKean J: Npsm R package nonparametric statistical methods using R. CRC Press, Boca Raton, FL, p287, 2019.

62. Winkel EG, Van Winkelhoff AJ, Timmerman MF, Van der Velden U and Van der Weijden GA: Amoxicillin plus metronidazole in the treatment of adult periodontitis patients. A double-blind placebo-controlled study. J Clin Periodontol 28: 296-305, 2001

63. Heta S and Robo I: The side effects of the most commonly used group of antibiotics in periodontal treatments. Med Sci (Basel) 6: E6, 2018.

64. Rodrigues RM, Gonçalves C, Souto R, Feres-Filho EJ, Uzeda M and Colombo AP: Antibiotic resistance profile of the subgingival microbiota following systemic or local tetracycline therapy. J Clin Periodontol 31: 420-427, 2004.

65. Fiehn NE and Westergaard J: Doxycycline-resistant bacteria in periodontally diseased individuals after systemic doxycycline therapy and in healthy individuals. Oral Microbiol Immunol 5: 219-222, 1990. 
66. Feres M, Haffajee AD, Goncalves C, Allard KA, Som S, Smith C, Goodson JM and Socransky SS: Systemic doxycycline administration in the treatment of periodontal infections (II). Effect on antibiotic resistance of subgingival species. J Clin Periodontol 26: 784-792, 1999.

67. Walker CB: The acquisition of antibiotic resistance in the periodontal microflora. Periodontol 2000 10: 79-88, 1996.

68. Herrera D, Roldán S, O'Connor A and Sanz M: The periodontal abscess (II). Short-term clinical and microbiological efficacy of 2 systemic antibiotic regimes. J Clin Periodontol 27: 395-404, 2000.

69. Ardila CM, Granada MI and Guzmán IC: Antibiotic resistance of subgingival species in chronic periodontitis patients. J Periodontal Res 45: 557-563, 2010.

70. Boda D, Negrei C, Nicolescu F and Balalau C: Assessment of some oxidative stress parameters in methotrexate treated psoriasis patients. Farmacia 62: 704-710, 2014.

71. Tamaki N, Tomofuji T, Ekuni D, Yamanaka R, Yamamoto T and Morita M: Short-term effects of non-surgical periodontal treatment on plasma level of reactive oxygen metabolites in patients with chronic periodontitis. J Periodontol 80: 901-906, 2009.

72. Rahman K: Studies on free radicals, antioxidants, and co-factors. Clin Interv Aging 2: 219-236, 2007.

73. Nakayama K, Terawaki H, Nakayama M, Iwabuchi M, Sato T and Ito S: Reduction of serum antioxidative capacity during hemodialysis. Clin Exp Nephrol 11: 218-224, 2007.

74. Kim JH, Baik HW, Yoon YS, Joung HJ, Park JS, Park SJ, Jang EJ, Park SW, Kim SJ, Kim MJ, et al: Measurement of antioxidant capacity using the biological antioxidant potential test and its role as a predictive marker of metabolic syndrome. Korean J Intern Med (Korean Assoc Intern Med) 29: 31-39, 2014.
75. Tamaki N, Tomofuji T, Maruyama T, Ekuni D, Yamanaka R, Takeuchi $\mathrm{N}$ and Yamamoto T: Relationship between periodontal condition and plasma reactive oxygen metabolites in patients in the maintenance phase of periodontal treatment. J Periodontol 79: 2136-2142, 2008.

76. Machida T, Tomofuji T, Ekuni D, Yamane M, Yoneda T, Kawabata Y, Kataoka K, Tamaki N and Morita M: Longitudinal relationship between plasma reactive oxygen metabolites and periodontal condition in the maintenance phase of periodontal treatment. Dis Markers 2014: 489292, 2014.

77. D'Aiuto F, Nibali L, Parkar M, Patel K, Suvan J and Donos N: Oxidative stress, systemic inflammation, and severe periodontitis. J Dent Res 89: 1241-1246, 2010.

78. Boda D: Cellomics as integrative omics for cancer. Curr Proteomics 10: 237-245, 2013.

79. Gupta A, Govila V and Saini A: Proteomics - The research frontier in periodontics. J Oral Biol Craniofac Res 5: 46-52, 2015.

80. Calenic B, Greabu M, Caruntu C, Nicolescu MI, Moraru L, Surdu-Bob CC, Badulescu M, Anghel A, Logofatu C and Boda D: Oral keratinocyte stem cells behavior on diamond like carbon films. Rom Biotechnol Lett 21: 11914-11922, 2016.

This work is licensed under a Creative Commons Attribution-NonCommercial-NoDerivatives 4.0 International (CC BY-NC-ND 4.0) License. 